\title{
Psychosocial Analysis of the Collective Processes in the United States After September 11
}

\author{
ALVARO RODRIGUEZ-CARBALLEIRA \\ FEDERICO JAVALOY \\ Department of Social Psychology \\ Faculty of Psychology \\ University of Barcelona \\ Barcelona, Spain
}

This article studies alterations in the values, attitudes, and behaviors that emerged among U.S. citizens as a consequence of, and as a response to, the attacks of September 11,2001 . The study briefly examines the immediate reaction to the attack, before focusing on the collective reactions that characterized the behavior of the majority of the population between the events of $9 / 11$ and the response to it in the form of intervention in Afghanistan. In studying this period an eight-phase sequential model (Botcharova, 2001) is used, where the initial phases center on the nation as the ingroup and the latter focus on the enemy who carried out the attack as the outgroup.

The study is conducted from a psychosocial perspective and uses "social identity theory" (Tajfel \& Turner, 1979, 1986) as the basic framework for interpreting and accounting for the collective reactions recorded. The main purpose of this paper is to show that the interpretation of these collective reactions is consistent with the postulates of social identity theory. The application of this theory provides a different and specific analysis of events. The study is based on data obtained from a variety of rigorous academic studies and opinion polls conducted in relation to the events of $9 / 11$.

In line with social identity theory, 9/11 had a marked impact on the importance attached by the majority of U.S. citizens to their identity as members of a nation. This in turn accentuated group differentiation and activated ingroup favoritism and outgroup discrimination (Tajfel \& Turner, 1979, 1986). Ingroup favoritism strengthened group cohesion, feelings of solidarity, and identification with the most emblematic values of the U.S. nation, while outgroup discrimination induced U.S. citizens to conceive the enemy (al-Qaeda and its protectors) as the incarnation of evil, depersonalizing the group and venting their anger on it, and to give their backing to a military response, the eventual intervention in Afghanistan. Finally, and also in line with the postulates of social identity theory, as an alternative to the virtual bipolarization of the conflict (U.S. vs al-Qaeda), the activation of a higher level of identity in the ingroup is proposed, a group that includes the United States and the largest possible number of countriesincluding Islamic states-in the search for a common, more legitimate and effective solution.

Keywords collective reactions, social identity, social categorization

35 The terrorist attack of $9 / 11$ in the United States was an exceptional event because of its dimension, its characteristics, its impact, and its political and social repercussions.

We wish to thank, without implicating, anonymous referees and Jordi Escartin, Clara Porrua, and Javier Martin for their contributions.

Address correspondence to Alvaro Rodriguez-Carballeira, Department of Social Psychology, Faculty of Psychology, University of Barcelona, Pg. Vall d'hebron 171, 08035-Barcelona, Spain. E-mail: alvaro.rodriguez@ ub.edu 
Consequently, the study of the attack has acquired great significance in a wide range of disciplines. This article studies the reaction of the U.S. population to the disaster of 9/11 from a psychosocial perspective.

The characteristics of $9 / 11$, in particular the unprecedented scale of the attack, planned from abroad and aimed at internal and emblematic targets in the United States, caused extraordinary commotion and gave rise to the need for a new definition of the situation. The authorities and the mass media immediately took leading roles in influencing the social construction of this phenomenon, in order to help shape the citizens' perception of events. These agents of influence were of great importance in establishing the new vision of the social reality that was largely shared by the U.S. population after $9 / 11$. It should be stressed that this study refers at all times to the reactions of citizens based solely on their perception of the facts. It would be interesting to examine more exhaustively the importance of these agents of influence-above all the mass media, but also those working in politics, business and other fields-in the construction of these perceptions, but this goes beyond the scope of this paper.

The terrorist attack led many U.S. citizens to reconsider, at least temporarily, certain values and attitudes, and some even altered some of their daily behavior, as will be presented later. It is in this broad sense that the article examines collective reactions or processes. In using the expressions collective processes or reactions generically, the paper alludes to the processes or reactions of the majority of the population, not to those of all U.S. citizens; this means that other types of reactions of a minority nature are not presented here.

This paper seeks to study the citizens' collective reaction from the moment in which the attack took place, to identify the principal or predominant tendencies in interpreting the attack, to see how certain attitudes and behaviors were modified, and to see how the citizens' response to 9/11 was shaped in the weeks that followed, until the government took the decision to intervene in Afghanistan. Specifically, the main aim of this paper is to show the extent to which this collective reaction to $9 / 11$ can be interpreted as being consistent with the postulates of "social identity theory" (Tajfel \& Turner, 1979, 1986). A people's social identity as a nation acquires greater importance when that nation is attacked from the outside. Starting from this basic premise of "social identity theory," a general explanation of the collective processes that emerged in response to the 9/11 attacks is undertaken here.

Social identity theory (Tajfel \& Turner, 1979, 1986) holds that because individuals feel they belong to a certain social group or category, they tend to highlight the characteristics that differentiate them from the members of other groups and, at the same time, they seek to create a positive image of their own. This group differentiation is the result of two factors. First, social categorization (Tajfel, 1978) increases the differences with respect to members of other categories while increasing the similarities with respect to those of one's own group. Second, social comparison means that a distinctive, yet positive, image is sought for the in-group. Insofar as individuals identify with a group, the sense of belonging to this group will guide their behavior. This sense of belonging leads them to experience an ingroup bias by which individuals will tend to favor their own group-ingroup favoritism - and to discriminate against other groups-outgroup discrimination.

Human behavior is typically driven by one's personal identity rather than by one's social identity or awareness of belonging to a group. In order for behavior to be guided by social identity, the latter must come to the fore; that is, it must be previously activated. The activation of social identity occurs in many different contexts, but especially in situations of conflict and rivalry, as studies conducted in a variety of contexts have repeatedly demonstrated. The classic study entitled the "Robbers Cave" (Sherif \& Sherif, 1953) showed that intergroup conflict can intensify identification with the group (corroboration of this finding is to be found, for example, in Ryen \& Kahn, 1975 and Price, 1989). Likewise, it might 
be concluded that $9 / 11$ led to an intensification of the social identity of the group-country being attacked, as this paper seeks to demonstrate below. Among the characteristics of 9/11 that might have brought about this intensification of identity, the following should be

90 highlighted: the fact that the aggression originated from outside the country, the fact that important symbols of the identity of the most powerful country in the world were attacked, the fact that nearly three thousand people were killed in the space of just a few minutes, and the fact that the events occurred in such a shocking way, broadcast live through the media.

\section{Sequential Analysis of the Collective Reactions After 9/11}

Below, the most salient values, attitudes, and behaviors manifest by the majority of the U.S. population between the $9 / 11$ attack and the response to it in the form of the intervention in Afghanistan are examined. Most of the empirical data used in this study are taken from academic research conducted on the events of 9/11 and, in some cases, from opinion polls

100 undertaken by prestigious entities, which in virtually all cases provide data that allow the situations before and after 9/11 to be compared. All these data have been used with prudence and caution, seeking confirmation in the results of several polls, in an awareness that certain inaccuracies and methodological limitations can be present in such polls, for example, certain biases in the formulation of questions or a failure to filter the sensitivity

105 to social desirability from the responses. However, the relations that are shown among the data presented do not allow cause-effect relations to be established. Equally, the results of separate polls that ask different questions do not allow one to conclude that the same person experienced each of the separate components.

In order to conduct a more detailed study of the collective reactions a model is used

110 as a guide. This model divides the sequence for analysis into eight phases. Specifically, it involves an adaptation of the cycle of violence model proposed by Botcharova (2001), which identifies the phases that lead to a violent act of revenge in a situation of conflict. These eight phases should be understood without any strictly defined chronology, since various aspects can occur, and indeed do occur, simultaneously. Only the first and last phases correspond 115 strictly to the origin and end of the process.

Before studying each phase separately, a description of the whole model is provided. Q2 An overall analysis of these eight stages shows that the first four focus their attention primarily on the ingroup, while the last four focus on the outgroup. A major similarity can be seen between the first four and the last four stages. In both cases the emphasis is placed

120 on the same four components, albeit in a different order. The components are behavioral, emotional, cognitive, and cultural in nature (see Table 1).

\section{Stage 1. Aggression/Act of Violence}

The attacks of 9/11 mark the beginning of the cycle. From the first moment, and primarily as a result of information provided by the television networks, U.S. citizens were fully

125 informed of the severity of the terrorist attack. Furthermore, given the scale of the attack and the symbolic importance of the targets chosen, it was clear that the attack had been aimed not at a specific institution, entity, or government, but rather at a whole country, and most U.S. citizens perceived it also as a direct attack on them (Schuster et al., 2001). The targets are among the most representative of the country's identity. These percep130 tions indicate that the social identity of the majority of those who consider themselves to be members of this country has been attacked. The aggression reveals the intensity of the conflict and, as predicted by social identity theory, it activates the social identity of the aggrieved party (Ryen \& Kahn, 1975; Price, 1989). This activated social identity now 
TABLE 1

\begin{tabular}{|c|c|c|}
\hline Stages & $\begin{array}{l}\text { Greatest } \\
\text { focus of } \\
\text { attention }\end{array}$ & $\begin{array}{l}\text { Component } \\
\text { receiving } \\
\text { greatest emphasis }\end{array}$ \\
\hline 1. Aggression/act of violence & Ingroup & Behavioral \\
\hline 2. Injury, pain, shock & Ingroup & Emotional \\
\hline 3. Realization of loss & Ingroup & Cognitive \\
\hline $\begin{array}{l}\text { 4. Suppression of grief and the seeking of refuge } \\
\text { in values }\end{array}$ & Ingroup & Cultural \\
\hline 5. Feelings of anger & Outgroup & Emotional \\
\hline 6. Desire for justice and the seeking of revenge & Outgroup & Cognitive \\
\hline 7. Telling and retelling the "right" conflict history & Outgroup & Cultural \\
\hline 8. An act of "justified" aggression & Outgroup & Behavioral \\
\hline
\end{tabular}

Adapted from Botcharova (2001).

has the capacity to guide the behavior of the group members, since this activation means that people tend to behave more as members of a group than as independent individuals.

Next the reaction of those affected in the place of the terrorist acts immediately after the attacks are briefly analyzed. This analysis is based on the images and testimonies offered in the mass media. From these data, it would appear that the scenes of panic described in the classic literature on catastrophes were relatively few. Panic reactions are the result of a complex chain of interactions when facing a situation perceived as constituting an imminent 140 threat to one's life, but in general such reactions are rare, and cooperative, coordinated behavior is predominant (Johnson, 1987). In this case, the main reason why panic did not ensue might have been because most people did not have a clear or direct perception of the risk their lives were under-the possibility of escape predominated over that of being trapped. Perhaps because they were unaware that the towers were about to collapse, $\mathbf{1 4 5}$ most of the people evacuated the buildings and dispersed in relative calm through the neighboring streets. In this situation of great tension, certain behaviors seem to have emerged spontaneously and these ensured that the escape was relatively orderly. The work of the fire services was also instrumental in this.

The behavior seen on 9/11 was not that predicted by the theories of irrational contagion, 150 but rather was more consistent with Turner and Killian's emerging norm theory (Turner \& Killian, 1987), which indicates how, in an unstructured situation, new behavior patterns may evolve that establish a new definition of the situation and are followed and thus legitimized by others. Indeed, in a study published in 1998, Aguirre Wenger, and Vigo used this theory to explain the initial reaction and subsequent evacuation of the WTC after a terrorist car- $\mathbf{1 5 5}$ bomb attack in 1993. However, the theory that perhaps best explains these events is that of social identity, and more specifically Reicher's (1987) application of this theory to explain crowd behavior during an emergency. Reicher explains that in such a situation, exemplified here by the evacuation of the Twin Towers, the group of people who find themselves caught up in the emergency construct a situational identity, on becoming aware that they share a 160 problem that can only be faced by proposing a collective solution. This solution will be consistent with the group's cultural values, beliefs and rules-rules of civic behavior that have been internalized in the socialization process (for example, "the evacuation should be conducted in an orderly fashion"). 
165 Stage 2. Injury, Pain, Shock

This phase alludes to the initial impact, the great damage caused, and the pain and grief of the survivors and of those who expressed solidarity with them. A number of studies provide data on the extent of the psychological damage inflicted by the attacks. A study conducted among the adult population of Manhattan between five and eight weeks after

$1709 / 11$ (Galea et al., 2002) found that incidences of depression and post-traumatic stress had practically doubled; cases of depression had risen from 4.9 to $9.7 \%$, and those of PTSD from Q4 3.6 to $7.5 \%$. PTSD reached $20 \%$ among the population living closest to the World Trade Center.

A further study conducted in the first week after 9/11 (Schuster et al., 2001) found

175 high levels of stress among adults throughout the United States, showing that those who did not actually experience the attack first-hand also presented symptoms of stress, especially those who considered themselves close to the victims. This was in fact in the case of most U.S. citizens, who in general regarded the attack as an aggression against their nation and against them as individuals. In fact, according to this study, $90 \%$ of the adult population

180 showed some degree of stress attributable to $9 / 11$; specifically, they "experienced at least one symptom 'a little bit'," and 44\% presented "at least one of five substantial stress symptoms" (these high percentages correspond to a sample of 560 adults interviewed between the third and fifth days after the attack).

In line with social identity theory (Turner, 1987, 102-103), the activation of a group's Q5

185 social identity-in this case, that of the U.S. people-implies the activation of its internal cohesion, giving rise, among other things, to a perception of common interests, cooperation, and demonstrations of empathic altruism towards members of the ingroup. The members of the group change their hierarchy of interests, giving priority to group interests over those of the individual. The results of the studies mentioned above in this section support the

190 activation of ingroup empathy and show how this empathy, expressed through the suffering experienced by the citizens, appears to be directly related to their proximity to the victims of the attack. Greater suffering occurred (i.e., a higher number of citizens were affected) when one of the following forms of proximity was recorded: greater geographical proximity to Ground Zero or the Pentagon (Galea et al., 2002; Schuster et al., 2001; Pew, 2002); a more

195 direct relationship, real or sensed, with the dead or the injured (Galea et al., 2002; Schuster et al., 2001); and greater number of television hours viewed on September 11 about the attack (Schuster et al., 2001).

September 11 also created a persistent sensation of fear among a large part of the U.S. population, alarmed by the possibility that there might be more attacks. This sensation was

200 accentuated by the anthrax letter scare. In this specific case in which feelings of fear and grief were activated, the anthrax letter attacks that occurred in many different parts of the country in the weeks following $9 / 11$ created such a tense atmosphere that some people no longer dared to open their mail. The first anthrax-related deaths and, in particular, the media coverage which reported many other suspected attacks contributed significantly to creating

205 this atmosphere that was tailor-made for the specific development of the phenomenon that some authors call "collective hysteria" but which others prefer to call "collective illusions" (Stewart, 1984), highlighting that what emerges first is a perceived threat (for example, the presence of anthrax), which triggers psychosomatic manifestations inside a network of people in an atmosphere of increased vulnerability. It is possible that a collective phenomenon

210 of this type might occur among a minority sector of the population. At least, this is the claim of Bartholomew and Wessely (2002), who, in a study of just such a situation, reported that this collective phenomenon, which they refer to as "mass sociogenic illness," did occur in certain sectors (they report that there were 2,300 false anthrax alarms during the first two weeks of October 2001, many of which included "sociogenic symptoms"). 
Widespread sensations of fear and of feeling under threat alter the relationship between $\mathbf{2 1 5}$ the ingroup and outgroup. Skitka, Bauman, and Mullen (2004) have shown that "higher levels of fear lead people to perceive outgroups as more violent and potentially threatening," a perception that is associated "with increased ethnocentrism, punitiveness, and political intolerance" (Marcus et al., 1995), features that are discussed below. Similarly, Coryn, Beale, and Myers (2004) found a clear relationship between the outbreak of a conflict 220 that gives rise to anxiety - as was the case of $9 / 11$ - and prejudice towards those who are perceived as its perpetrators.

\section{Stage 3. Realization of Loss}

The faith of the U.S. people in their country's ability to protect them was called into question in the aftermath of the attack on the greatest symbols of economic power and security. Vulnerability and fear now more obviously present and the feeling of danger caused a sector of the population to change their lifestyles, reducing many of their favorite activities such as eating out, shopping, traveling, or going to places of entertainment (Pyszczynski, Solomon, \& Greenberg, 2002). A number of surveys supported these sweeping changes in lifestyle; for example, $42 \%$ of the population said they spent more time near home and $\mathbf{2 3 0}$ family (in New York, the figure reached 57\%); $25 \%$ reported opening their mail with greater care; and $20 \%$ stopped traveling by air (Pew, 2002).

A large number of U.S. citizens expressed an awareness of the fact that their country was vulnerable and acted accordingly, above all by reducing their activities away from home and seeking refuge within the most intimate part of the ingroup. Among the effects that $\mathbf{2 3 5}$ derive from activation of the social identity are the activation of pro-social tendencies, of cooperation and of feelings of solidarity towards the group, including also the motivation to commit oneself to the group and to dedicate considerable amounts of effort and resources to the group. The strength of this commitment can even lead on occasion to heroic acts of immolation on behalf of the group (Turner, 1987, 105). In the United States such acts 240 ranged from the strenuous efforts of the fire fighters and security forces to the substantial response of citizens in terms of donating blood and offering their skills and money (Olson, 2002).

\section{Stage 4. Suppression of Grief and the Seeking of Refuge in Values}

In this stage a certain degree of self-control over the pain and fear is foreseen, fostered by a $\mathbf{2 4 5}$ strengthening of values that enables people to face up better to the challenges of daily life.

In order to cope with future threats and to avoid being overcome by the loss, in this phase it is postulated that many people sought to suppress their grief. This reaction was favored by widespread efforts to restore a sense of safety and national self-esteem and identity, and thus to mitigate feelings of terror (Kliman \& Llerena-Quinn, 2002). Similarly, it is postulated that 250 many citizens felt a need to recover their self-confidence and self-control. As usually occurs in situations of conflict, according to social identity theory, a strong sense of social identity emerged among the population, in this case as a nation that has been assaulted; the sense of identification with the country was strengthened and made explicit. U.S. citizens sought refuge in their most solid and readily available cultural values, fundamentally patriotism $\mathbf{2 5 5}$ and religion. Research shows how patriotic and nationalistic sentiments are intensified in times of international conflict (Feshbach, 1987).

Social identity theory has examined this link between identity and ideology, demonstrating that social identification with the group implies an identification with the beliefs and ideology that it defends (Turner, 1982, 24). Thus, reactivating the values of the nation-group 260 contributes to a reestablishment of the most valuable content of social identity and, in this way, to a re-establishment also of self-esteem and pride. 
The significance attached to the role of religion in U.S. life rose markedly after 9/11: $78 \%$ of the population reported it as being important in their lives, and $74 \%$ acknowledged

265 having prayed more after $9 / 11$. These figures are unprecedented in the last forty years of Gallup polls; nonetheless, they were not accompanied by a greater acceptance of religious minorities (Pew, 2001; AEI, 2002a).

Patriotic feeling increased notably, with similar conclusions being offered by various polls. Some of the most thorough in this aspect (compiled in AEI, 2002a, 2002b) showed

270 that $87 \%$ of the population claimed to value their country more after $9 / 11$, and $60 \%$ said that they had become more patriotic. Pride in being a U.S. citizen soared. Before $9 / 11,55 \%$ considered themselves "extremely proud" of their citizenship; after 9/11, this figure rose to $74 \%$. This devotion to the country formed part of the sudden, widespread rise in the esteem for what is ours: the things that characterize the culture, the people, and their identity .

275 Whereas before 9/11 the majority (62\%) stated that they saw a division in the United States in terms of the values held to be most important, after the attacks a larger majority (74\%) considered the country to be united (AEI, 2002a, 2002b). Among the many manifestations of patriotism after $9 / 11$, flying the flag became a kind of $\mathrm{fad}$. Though the flag was already a highly significant symbol, it acquired new forms of expression and a new meaning. For a

280 majority of people, religion and patriotism appear to have provided solid values in which to seek refuge, being representative of their culture and linked to the identity of the U.S. people and nation.

The proponents of "terror management theory" (Rosenblatt et al., 1989; Greenberg et al., 1990; Greenberg, Solomon, \& Pyszczynski, 1997) offer a complementary explanation

285 for this reactivation of the love of one's own values - at least for those of religion and patriotism, for which the statistics point to just such a reactivation (an explanation that is fully compatible with social identity theory). These authors forward the hypothesis that $9 / 11$ reminded the U.S. people of their mortality (Pyszczynski, Solomon, \& Greenberg, 2003) (attack on the ingroup); it intensified their reverence for all that was admirable in their

290 culture (a manifestation of ingroup favoritism); and it exacerbated their negative reactions toward those who were critical of their country (a manifestation of outgroup discrimination). The proponents of terror management theory show that a realization of one's own mortality can: (1) increase ingroup affiliation and prejudices (Harmon-Jones et al., 1996), (2) increase hostility and aggression towards outgroup members (McGregor et al., 1998), (3) strengthen

295 ties with fellow ingroup members who conform to cultural expectations (Greenberg et al., 1990), and (4) increase nationalism (Arndt et al., 2002). These responses help to explain the phenomena of anger and hostility which are analyzed in the next section.

\section{Stage 5. Feelings of Anger}

Fear and grief can be transformed into anger. According to Freyd (2002), this can occur both 300 individually and collectively. When feelings of fear are accentuated, anger can constitute a means of strengthening one's sense of being in control. Anger and fear lead people to draw clearer distinctions between the ingroup and the outgroup (Baron et al., 1992; Stephan \& Stephan, 1985). If the ingroup is seen as being strong, it is more likely that anger and confrontation will be manifest as a means of responding to the conflict between groups

305 (Smith, 1993, 1999) and that more optimistic assessments will be made of future risks (Lerner et al., 2003). Anger and rage seek an outlet; they require that the situation be defined so that the guilty party can be identified, and recognized and confronted as the enemy. In this case the enemy, al-Qaeda, was promptly identified and the situation defined. The outside enemy, the outgroup, was thus defined and the sentiments of anger and rage

310 felt by the members of the ingroup were channeled against them. The social identity of the ingroup that has been activated also implies the activation of animosity towards the outgroup 
Q7 aggressor. According to the theory of a group's social identity (Turner, 1987), as individuals perceive themselves to be members of a group and to identify with it, their behavior is less determined by personal interests; it undergoes a "depersonalization." This depersonalization also affects their way of perceiving the members of the outgroup, who are seen not as $\mathbf{3 1 5}$ individuals, but as elements of the same category, as homogenous, interchangeable beings (the attribution of homogeneity to the outgroup).

The Arab identity of the attackers meant that the social categorization of the outgroup was provisionally extended to include all citizens of Arab origin and the like, among whom the enemy, the members of al-Qaeda, must lie. For Gerstenfeld $(2002,62)$, a nation's social identity takes on particular relevance in the context of an international conflict; in the case of the United States, certain subjective definitions of the country's social identity exclude all descendants of non-Europeans (Perry, 2001), and the feeling of patriotism is associated with feelings of prejudice and discrimination towards the outgroup (Kashti, 1996; Kelman, 1996). Ethnicity has a powerful, almost universal effect on social categorization (Fiske \& 325 Neuberg, 1990). These reasons help explain why part of the anger was directed against Arabs, the ethnic group from which al-Qaeda emerged. Indeed, the hostility spread, and all people "of Middle Eastern appearance" were tarred with the same brush.

Various surveys showed that anger and mistrust toward persons from the Middle East rose among the U.S. population. One year after $9 / 11,54 \%$ believed that any new attack would 330 most likely be perpetrated by Islamic terrorists still living in the United States (Pew, 2002). This helps elucidate how fearful groups can become hostile, how from feeling threatened they become threatening themselves.

The anger felt by many U.S. citizens indeed manifest itself, in some cases, in hostility toward people of Arabic or similar origin, with reports of gun or knife attacks, arson, attacks 335 on mosques, bomb threats and insults, in addition to the murder of a Sikh wearing a turban who was mistaken for a Muslim. This was counterbalanced by many acts of kindness and understanding: for instance, protecting mosques or accompanying Arab women and children to markets and schools (Lee, 2002, 132-135).

Indeed, 9/11 changed the context of identification for thousands of U.S. citizens. This $\mathbf{3 4 0}$ was especially true of immigrants, and nowhere more so than among those from the Middle East, who were already associated in people's minds with terrorism (Perry, 2001). For instance, after the bomb attack in Oklahoma in 1995, the attention of the media and the security forces turned immediately toward the Arab community, though eventually it transpired that the perpetrators of the attack were U.S. citizens of European descent.

\section{Stage 6. Desire for Justice and the Seeking of Revenge}

As discussed above, social identification with a group implies identification with the beliefs and ideology that it upholds. On studying the behavior of the masses, Reicher (1982,73-74) also stresses the importance of ideology and claims that it is the collective ideology that will set the boundaries on the behavior to be taken in a given situation. And at the root of $\mathbf{3 5 0}$ all ideologies of protest, there lies the sense of injustice. This sense of injustice emerges when the members of a group consider that they have not been treated as they deserve. If this situation of injustice is attributed to impersonal causes (such as a economic crisis), the reaction may be one of fear, resignation, or apathy, but if it is attributed to a specific group of persons (in this case, al-Qaeda), the reaction will be one of anger, and this emotion generates 355 the energy that permits the aggrieved party to fight against those who have caused this sense of injustice (Klandermans, 1997, 18). Thus, out of this sense of injustice, the anger and the determination to fight to see that justice is done are born. Therefore, this sense of injustice is also a source of ideological legitimacy for fighting against the aggression suffered. The 
360 importance of the role of the mass media in the social construction of this sense of injustice should be stressed, though it will not be analyzed any further here.

Angry and intimidated people are likely to believe that in order to get back to normal, that is, to recover their sense of security, they need to eliminate the source of the damage (Botcharova, 2001). The data on this do not point clearly to a desire to seek revenge or 365 to eliminate the enemy, but they do show a high degree of support for a broad military response. Surveys carried out after 9/11 (compiled in AEI, 2002a) indicated that around $90 \%$ of the U.S. population supported military action against the perpetrators of the attacks (taking for granted that this would involve an intervention against another country). More than $70 \%$ were willing to give up certain personal freedoms in order to reduce the threat

370 of terrorism and $55 \%$ were willing, for the same reason, to give up certain civil liberties as well (AEI, 2002a).

\section{Stage 7. Telling and Retelling the "Right" Conflict History}

When the sense of confrontation with another group is particularly acute, the strength of ingroup identification also acquires greater intensity (Perreault \& Bourhis, 1999, 92). This suggests that the $9 / 11$ attack activated, to a large extent, the social identity of U.S. citizens as a nation. Thus, the bipolar categorization between the ingroup and outgroup leads more readily to the nurturing of this ingroup bias, in other words, to a situation in which people tend to favor their own group (ingroup favoritism) and to discriminate against the outgroup (outgroup discrimination) (Tajfel \& Turner, 1979, 1986). This bias can lead to extremes,

380 with the construction of an image of the ingroup as the incarnation of good and that of the outgroup as the incarnation of evil.

The U.S. government revived a discourse that was similar to that used during the Cold War to legitimize their policies, but replacing the Communist threat with that of terrorism. The politicians' discourse and the predominant messages in the mass media meant that the

385 complexity of the international situation was largely reduced to a battle between "us," the righteous, the human, and "them," the evil and inhuman. This tendency is characteristic of ideological systems when it becomes radicalized (Javaloy, 1993; Javaloy, Rodríguez Carbailleira, \& Espelt, 2001,319-320,338). The others have no right to a place in the human community, and so inhuman treatment is justified (Kliman \& Llerena-Quinn, 2002, 11).

390 This discourse promotes a simplistic, reductionist dichotomy which legitimizes the use of force. On September 19, 2001, the U.S. government announced "Operation Infinite Justice" (renamed "Operation Enduring Freedom" six days later), and in January 2002 named the countries that constituted the "Axis of Evil." As Unger $(2002,48)$ suggests, the hidden ideology or worldview that underpins the fanaticism or radical Islamic fundamentalism is also present in the West - on a different scale, but of the same nature.

The events of 9/11 created heroes and villains in keeping with the same bipolar vision of the world. The media played a major part in this process. On the side of good, the new heroes of the United States were the fire fighters, many of whom had died when the towers collapsed, and the New York fire service worked fearlessly among the flames and

400 the wreckage. The fire fighters acquired mythical status in the public mind. Some people even crossed themselves in their presence; all kinds of fire service mementos were sold (also becoming a kind of $\mathrm{fad}$ ) and new fashion designs were made based on their uniforms. On the side of evil, the following case serves to illustrate the reigning confusion and manipulation: Reporting the reactions to $9 / 11$ in the Arab world, the television station CNN showed pictures of Palestinian children jumping for joy, pictures which were seen all over the world and were repeated time and again - until it was discovered that they had been filmed two years earlier, and that the children had not been expressing their joy at the events of 9/11. 
But of course the message had already been transmitted that these children were the villains in the piece.

An old myth of particular interest is the United States' appropriation of the name of $\mathbf{4 1 0}$ the continent to refer to itself as "America." The name is widespread today; it is used by both U.S. citizens and foreigners. The emblematic sentence God bless America is a classic example. Significantly also, 9/11 was named Attack on America.

September 11, however, was widely interpreted not only as an attack on the United States, but as an attack on the western world in general. It is no less true that the threats $\mathbf{4 1 5}$ issued by Osama Bin Laden-who also had a vested interest in simplistic dichotomies typical of fanatical thinking - contributed to this notion by declaring war between "Islam and the infidels," between the "Islamic nation" and the rest of the world.

\section{Stage 8. An Act of "Justified” Aggression}

According to the analysis undertaken up to this point, from the perspective of social identity it is clear that the situation presented quite a number of the conditions whereby the attitudes of the majority would favor an aggressive response to 9/11. In analyzing more thoroughly this type of violent behavior, Opotow (1990) concluded that if the outgroup is considered the incarnation of evil and its members are seen as homogenous beings, this tendency can, in certain cases, lead to the infra-humanization of the enemy and behavior of extreme $\mathbf{4 2 5}$ violence. Likewise, Reicher $(1982,76)$ claims that seeing the others as being homogenized by their social identity, and not on the basis of their personal characteristics, can lead to a loss of morality and even to the use of torture and extreme cruelty. In this case, the enemy was defined as the incarnation of evil (al-Qaeda), its components as terrorists (members of al-Qaeda and its supporters), and as such greatly dehumanized.

The intervention in Afghanistan against al-Qaeda and the Taliban regime that supported and sheltered it was the aggressive response to 9/11. Those proposing an alternative based on a constructive approach to conflict resolution, in line with what are known as models of "interactive conflict resolution (ICR)" (Fisher, 1993, 1996), were in a clear minority. Below is a list of some other factors that may have persuaded many members of the U.S. 435 population to choose the destructive path, in support of their government:

- A possible hypothesis is that the great dimension of the 9/11 attack, both in real and in symbolic terms, might have contributed to the fact that the dominant perspective that came to be held was that of aggression, rather than conflict. Before 9/11 the conflict between the United States and Islamic radicals had taken the form of sporadic terrorist attacks 440 on U.S. interests, but the attacks in New York and Washington could be interpreted as such a clear vindication of the violent option that it drove the U.S. population to see the conflict above all in unilateral terms of aggressors/victims and to situate the analysis in the aftermath of a direct act of aggression.

- It is easier to explain the pressure to respond by using force from the perspective of $\mathbf{4 4 5}$ aggression. This perspective was further facilitated by the deeply ingrained cultural values of defense and security, patriotism, the tradition as the world's greatest power of military intervention in foreign countries, and the opinion of the vast majority of the population in support of an aggressive response.

- Consistent with these comments is the predominance of certain cognitive processes that $\mathbf{4 5 0}$ limited the ability to see the conflict from a broader perspective. Deutsch (1969) stresses that the tension resulting from an escalation of conflict induces subjects to focus on the immediate, shortening the time perspective, narrowing the range of perceived alternatives, polarizing thought in simplistic black-and-white terms, inducing stereotyped responses, and increasing the pressure toward social conformity. Weitzman and Kew (2002) note 
other biases in their study on $9 / 11$, such as the "fundamental attribution error" (Jones \& Nisbett, 1971), which attributes the aggressive actions of the other to the other's personal characteristics, and "ethnocentricism," which persuades us of our superior strength when others attack us and to think that when we attack the other will collapse and divide (Brewer, 1986). These biases affect the analysis of the phenomenon and may lead to mistaken or hurried decisions. However, in this case, this possible error of attribution needs stronger empirical support.

Once the violent response had been taken, the perception of U.S. citizens of having punished the aggressor should have spelt the end of the cycle of violence; however, a number

465 of factors might have impeded this, including the great impact of 9/11, the ongoing antiterrorist operation, and the perception among the people of the possibility of new attacks-a perception based on the warnings of their own government. In terms of social identity theory and the eventual closing of the cycle, what is required is a gradual reduction in the activation of U.S. social identity and of the phenomena that derived from this activation. A shift has

470 already begun in this direction. One year later, by way of example, since no cause-effect relations can be established, "many of the dramatic reactions of the public to the events of 9/11 had slowly faded" (Pew, 2002).

\section{Discussion}

This attempt at undertaking a global explanation of the collective reaction of the U.S. citizens 475 to the events of 9/11 has based its analysis on the positions adopted by a majority sector of this population. In speaking of the collective reaction of the citizens, it is understood that this reaction emerged not from a direct knowledge of the events, but rather from the perception of these events constructed through the mass media and, in particular, through the definition of the situation transmitted by the authorities who did have direct knowledge

480 of what was actually occurring. The credibility afforded by the citizens to the different sources of information that were available contributed to shaping their eventual perception of events.

The use of Botcharova's (2001) eight-phase model enables a detailed, and at the same time a fairly broad-ranging, study of the collective reactions to be undertaken. The phases

485 analyzed should not be seen as rigid and impermeable, but rather as presenting common elements that can and do occur simultaneously, since they are illustrative of a process that unfolds in an interactive manner. The phases of this process describe the principal elements of social behavior: affective, cognitive, cultural and of action, centered first on the ingroup and then on the outgroup (Table 1). Thus, they describe a cycle that is set in motion and

490 brought to a conclusion, although the way in which the open conflict is terminated might have followed other phases that did not lead to revenge or punishment. If a review is made of the eight phases, it can be seen that the coincidence of the citizen response appears most likely in the first four, centered on the ingroup, and least likely in the last four, centered on the outgroup, in particular in the last and definitive phase, that of violent response. The

495 model's weaknesses might be identified as including its failure to consider the interaction of interpersonal relations and the existence of social networks, which are fundamental in the transmission of collective phenomena; similarly, it fails to include the structural variables that are so important in the analysis of phenomena of collective conflicts.

The application of social identity theory as a global framework for the analysis un500 dertaken here provides a highly coherent explanation of events and enables us to make some predictions concerning the future. In short, after $9 / 11$, there first occurred the marked salience of the aggrieved ingroup and the activation of mechanisms of ingroup favoritism. The aggression from outside, together with the interpretation the citizens received of it by 
way of the authorities and the media, reminded the majority of U.S. citizens that they were members of a group; it increased feelings of identification, self-esteem, solidarity and cohe- $\mathbf{5 0 5}$ sion; united their beliefs; enhanced cooperation; and strengthened their sense of belonging and their commitment. Subsequently, outgroup discrimination came to the fore, activating feelings of animosity towards the outgroup as if they formed a homogenous whole, which was infra-humanized, seen as being the incarnation of evil and declared as the enemy that must be defeated (Turner, 1987).

The collective reaction initiated on 9/11 was characterized by a highly intense activation of the emotions, including, as has been described: feelings of pain, grief, vulnerability, fear, religious sentiments, feelings of patriotism, of anger, hostility, and revenge, among others. The fact that this intensification of the emotions remained activated hindered part of the population from undertaking a calm, cognitive processing of events, and led to a $\mathbf{5 1 5}$ number of limited reactions, not unlike those that Deutsch (1969) describes in similar circumstances: a focus on the immediate situation restricting a broader time perspective and a simplistic polarization (good-bad, security-insecurity, victors-humiliated) reducing the range of alternatives and facilitating stereotypical responses.

The fight against the enemy was not concluded following the intervention in $\mathbf{5 2 0}$ Afghanistan, but rather was left open indefinitely. As the enemy has not been eliminated, he could attack again. This suggests that, to a certain degree, the suspicion of future enemy attacks maintains the social identity and the biases of favoritism and discrimination activated. Warnings of these threats can be used for political advantage. Specifically, Landau et al. (2004) found that reminding experimental subjects about 9/11 increased the popular- $\mathbf{5 2 5}$ ity for President Bush, and an analysis of several time-series of polls conducted by Willer (2004) "showed a consistent positive relationship between terror warnings and presidential approval." The maintenance of these alerts may contribute, as Esses, Dovidio, and Hodson $(2002,79)$ note, to a rise in authoritarianism, as is often the case in times of uncertainty and perceived threat. This in turn is accompanied by a deepening of mistrust toward im- $\mathbf{5 3 0}$ migrants, marking an abrupt about-turn in the distinctively favorable trend of previous years.

In line with social identity theory, it might be predicted that attacks organized between two groups - here, the United States and al-Qaeda — serve to intensify even further the social identity of the parties to a conflict. This leads to greater bipolarization and an escalation in $\mathbf{5 3 5}$ the conflict. History also appears to show us that vengeance perpetuates trauma and deepens the spiral of conflict. Although al-Qaeda is a small organization that cannot be compared with the world's leading power, its worldwide network and its potential for growth are sufficient to keep this bipolarization alive. Thus, as long as the United States understands that al-Qaeda has not been eliminated, the prognosis is that the fight will be prolonged $\mathbf{5 4 0}$ indefinitely.

A strategy recommended by social identity theory for resolving the conflict is to seek a higher and wider categorization for the ingroup. What is required is to bring to the fore an ingroup identity at a higher level (for example, the democratic countries of the world, or the UN) so that the new, wider identity might bring about a change in the bipolarization $\mathbf{5 4 5}$ established. In the case of the United States such a strategy would mean seeing the situation in terms of a new, more inclusive "us," an alliance with the highest possible number of countries, including above all those considered to be Islamic countries, so as to agree on the best way of dominating al-Qaeda. Politically, this would have allowed the United States to capitalize on the great international solidarity expressed after $9 / 11$ and to construct a grand $\mathbf{5 5 0}$ alliance as the basis for achieving the maximum degree of consensus possible in order to respond to the aggressors. In support of this strategy is the fact that al-Qaeda has carried out terrorist attacks in various countries and has declared all countries not belonging to 
the "nation of Islam" as enemies. This alternative is only considered here theoretically, as derived from social identity theory, without attempting to assess the practical difficulties that this option would have entailed.

In short, the perspective provided by social identity theory suggests that another response was possible, another way in which to seek justice, the road of international agreement in opposition to al-Qaeda, the construction of a large endogroup united behind this

560 cause. This could have involved many more countries than those that actually lent their support. International cooperation of this nature would have contributed to changing the "U.S. vs. al-Qaeda" bipolarization and would have achieved considerable world legitimacy. It is reasonable to think that this alliance of coordinated countries would have enjoyed greater success in the fight against al-Qaeda and would have contributed to a greater perception of 565 peace and security in the world.

The United States would have exercised a leadership based more closely on cooperation than imposition. It is reasonable to think that the United States would have earned prestige in international public opinion. However, it is more difficult to hypothesize the extent to which the U.S. population would have allowed its government to slow down the process

570 while it sought the wider consensus and international involvement in its response. Some sectors would have supported this path, however the emotional intensification described above placed pressure on the government to take a rapid response.

However, if the United States maintains its unilateral struggle against al-Qaeda, even though it receives support from some countries, it might lose international legitimacy, above all if it carries out indiscriminate attacks or if these are interpreted as anti-Islamic, or if it commits acts that are questionable on legal and humanitarian grounds, such as the holding of prisoners at Guantanamo. If this does occur, the social identity of al-Qaeda might gain greater saliency among the sympathizers of fundamental Islam and attract other "anti-imperialist," radical activists.

580 Before concluding, it is important to mention certain possible limitations in this study in relation to the data presented, since some are drawn from opinion polls in which the methodological controls are not always entirely rigorous. With the care that these and other limitations dictate, it is fair to claim that the analysis undertaken here of the collective reaction of U.S. citizens following the events of $9 / 11$, based on the focus provided by social 585 identity theory, offers a consistent explanation of the events. Nevertheless, the events of 9/11 should continue to be studied from other perspectives so that we might further our understanding of such an important episode.

\section{References}

Aguirre, B. E., D. Wenger, and G.Vigo. 1998. Test of emergent norm theory of collective behavior. Sociological Forum 13: 301-320.

American Enterprise Institute (AEI). 2002a. American public opinion on de the war on terrorism. www.aei.org/ps/psfront.htm.

American Enterprise Institute (AEI). 2002b. Polls on Patriotism. www.aei.org/ps/psbowman10.pdf

Arndt, J., J. Greenberg, J. Schimel, T. Pyszczynski, and S. Solomon. (2002). To belong or not to belong, that is the question: Terror management and identification with ethnicity and gender. Journal of Personality and Social Psychology 83: 26-43.

Baron, R. S., M. L. Inman, C. F. Kao, and H. Logan. (1992). Negative emotion and superficial social processing. Motivation and Emotion 16: 323-346.

Bartholomew, R. E., and S. Wessely. 2002. Protean nature of mass sociogenic illness. British Journal of Psychiatry 180(4): 300-306.

Botcharova, O. 2001. Implementation of track to diplomacy: Developing a model of forgiveness. In Forgiveness and reconciliation: Religion, public policy, and conflict transformation, ed. G. Raymond, S. J. Helmich, and R. L. Petersen, 279-305. Philadelphia: Templeton Press. 
Brewer, M. B. 1986. The role of ethnocentrism in intergroup conflict. In Psychology of intergroup relations, 2nd ed., ed. S. Worchel and W. G. Austin, 88-102). Chicago: Nelson-Hall.

Coryn, C. L., J. M. Beale, and K. M. Myers. 2004. Response to September 11: Anxiety, patriotism, and prejudice in the aftermath of terror . Current Research in Social Psychology 9(12): 165-183.

Deutsch, M. 1969. Conflicts: Productive and destructive. Journal of Social Issues 25: 7-41.

Esses, V. M., J. F. Dovidio, and G. Hodson. 2002. Public attitudes toward immigration in the United States and Canada in response to the September 11, 2001 "Attack on America." Analyses of $\mathbf{6 1 0}$ Social Issues and Public Policy 2(1): 69-85.

Feshbach, S. 1987. Individual aggression, national attachment, and the search for peace. Aggresive Behavior 5: 315-326.

Fiske, S. T., and S. L. Neuberg. 1990. A continuum of impression formation, from category-based to individuating processes: Influences of information and motivation on attention and interpretation. 615 In Advances in experimental social psychology, Vol. 23, ed. M. P. Zanna, 1-74. New York: Academic.

Freyd, J. 2002. In the wake of terrorist attack, hatred may mask fear. Analyses of Social Issues and Public Policy 2(1): 5-8.

Galea, S., J. Ahern, H. Resnick, D. Kilpatrick, M. Bucuvalas, J. Gold, and D. Vlahov. 2002. Psy- 620 chological sequelae of the September 11 terrorist attacks in New York City. The New England Journal of Medicine 346(13): 982-987.

Gerstenfeld, P. B. 2002. A time to hate: Situational antecedents of intergroup bias. Analyses of Social Issues and Public Policy 2(1): 61-67.

Greenberg, J., T. Pyszczynski, S. Solomon, A. Rosenblatt, M. Veeder, S. Kirkland, and D. Lyon. 1990. 625 Evidence for terror management theory II: The effects of mortality salience on reactions to those who threaten or bolster the cultural worldview. Journal of Personality and Social Psychology 58: $308-318$.

Greenberg, J., S. Solomon, and T. Pyszczynski. 1997. Terror management theory of self-esteem and social behavior: Empirical assessments and conceptual refinements. In Advances in experimental $\mathbf{6 3 0}$ social psychology, Vol. 29, ed. M. P. Zanna, 61-139. New York: Academic Press.

Harmon-Jones, E., J. Greenberg, S. Solomon, and L. Simon. 1996. The effects of mortality salience on intergroup bias between minimal groups. European Journal of Social Psychology 26: 677-681.

Javaloy, F. 1993. El paradigma de la identidad social en el estudio del comportamiento colectivo y de los movimientos sociales. Psicothema 5: 277-286.

Javaloy, F., A. Rodríguez-Carballeira, and E. Espelt. 2001. Comportamiento colectivo y movimientos sociales. Madrid: Prentice-Hall.

Johnson, N. R. 1987. Panic and the breakdown of social order: Popular myth, social theory, empirical evidence. Sociological Focus 20: 171-183.

Jones, E. E., and R. E. Nisbett. 1971. The actor and the observer: Divergent perceptions of the causes of behavior. Morristown, NJ: General Learning Press.

Kashti, Y. 1996. Patriotism as identity and action. In Patriotism in the lives of individuals and nations, ed. D. Bar-Tal and E. Stabu, 151-164. Chicago IL: Nelson-Hall.

Kelman, H. C. 1996. Nationalism, patriotism, and national identity: Social-psychological dimensions. In Patriotism in the lives of individuals and nations, ed. D. Bar-Tal and E. Staub, 165-189. 645 Chicago, IL: Nelson-Hall.

Klandermans, B. 1997. The social psychology of protest. Cambridge: Blackwell.

Kliman, J., and R. Llerena-Quinn. 2002. Dehumanizing and rehumanizing responses to September 11. Journal of Systemic Therapies 21(3): 8-18.

Landau, M., S. Solomon, J. Greenberg, F. Cohen, T. Pyszczynski, J. Arndt, C. H. Miller, D. M. Ogilvie, 650 A. Cook. 2004. Deliver us from evil: The effects of mortality salience and reminders of 9/11 on support for President George W. Bush. Personality and Social Psychology Bulletin 30(9): $1136-1150$.

Lee, K. S. 2002. Building intergroup relations after September 11. Analyses of Social Issues and Public Policy 2(1): 131-141.

Lerner, J. S., R. M. González, D. A. Small, and B. Fischhoff. 2003. Effects of fear and anger on perceived risk of terrorism: A national field experiment. Psychological Science 14: 144-150. 
Marcus, G. E., J. L. Sullivan, E. Theiss-Morse, and S. L. Wood. 1995. With malice toward some: How people make civil liberties judgments. New York: Cambridge University Press.

McGregor, H. A., J. D. Lieberman, S. Solomon, J. Greenberg, J. Arndt, L Simon, and T. Pyszczynski. 1998. Terror management and aggression: Evidence that mortality salience motivates aggression against worldview threatening others. Journal of Personality and Social Psychology 74: 590-605.

Olson, B. D. 2002. Applied social and community interventions for crisis in times of national and international conflict. Analyses of Social Issues and Public Policy 2(1): 119-129.

Opotow, S. 1990. Moral exclusion and injustice: An introduction. Journal of Social Issues 46(1): $1-20$.

Perreault, S., and R. Bourhis. 1999. Etnocentrism, social identification, and discrimination. Personality and Social Psychology Bulletin 25: 92-103.

Perry, B. 2001. In the name of hate: Understanding hate crimes. New York: Routledge.

670 Pew Research Center. 2001. Post September 11 attitudes. www.people-press.org

Pew Research Center. 2002. One year later: New Yorkers more troubled, Washingtonians more on edge. www.people-press.org

Price, V. 1989. Social identification and public opinion: Effects of communicating group conflict. Public Opinion Quarterly 53: 197-224.

675 Pyszczynski, T., S. Solomon, and J. Greenberg. 2003. In the wake of 9/11: The psychology of terror. Washington D.C.: American Psychological Association.

Reicher, S. D. 1982. The determination of collective behaviour. In Social identity and intergroup relations ed. H. Tajfel. Cambridge: Cambridge University Press.

Reicher, S. D. 1987. Crowd behaviour as social action. In Rediscovering the social group: A selfcategorization theory, ed. J. C. Turner, M. A. Hogg, P. J. Oakes, S. D. Reicher, and M. S. Wetherell; Oxford: Blackwell.

Rosenblatt, A., J. Greenberg, S. Solomon, T. Pyszczynski, and D. Lyon. 1989. Evidence for terror management theory I: The effects of mortality salience on reactions to those who violate or uphold cultural values. Journal of Personality and Social Psychology 57: 681-690.

685 Ryen, A. H., and Kahn. 1975. The effects of intergroup orientation on group attitudes and proxemic behaviour: A test of two models. Journal of Personality and Social Psychology 31: 302310.

Schuster, M. A., B. D. Stein, L. H. Jaycox, R. L. Collins, G. N. Marshall, M. N. Elliott, A. J. Zhou, D. E. Kanouse, J. L. Morrison, and S. H. Berry. 2001. A national survey of stress reactions after the September 11, 2001, terrorist attacks. The New England Journal of Medicine 345(20): $1507-1512$.

Sherif, M., and C. W. Sherif. 1953. Groups in harmony and tension. New York: Harper \& Brothers.

Skitka, L. J., C. W. Bauman, and E. Mullen. 2004. Political tolerance and coming to psychological closure following the September 11, 2001, terrorists attacks: An integrative approach. Personality and Social Psychology Bulletin 30(6): 743-756.

Smith, E. R. 1993. Social identity and social emotions: Toward new conceptualizations of prejudice. In Affect, cognition, and stereotyping: Interactive processes in group perception, ed. D. M. Mackie and D. L. Hamilton, 297-315. San Diego: Academic Press.

Smith, E. R. 1999. Affective and cognitive implications of a group becoming part of the self: New models of prejudice and of the self-concept. In Social identity and social cognition, ed. D. Abrams and M. A. Hogg, 183-196. Oxford: Basil Blackwell.

Stephan, W. G., and C. W. Stephan. 1985. Intergroup anxiety. Journal of Social Issues 41: 157-175.

Stewart, R. 1984. On the nature of mass histeria. Paper presented at the annual meeting of the Midwest Sociological Society, Chicago.

705 Tajfel, H. 1978. Social categorization, social identity and social comparison. In Differentiation between social groups: studies in the social psychology of intergroup relations, ed. $\mathrm{H}$. Tajfel. London: Academic Press.

Tajfel, H., and J. C. Turner. 1979. An integrative theory of intergroup conflict. In The social psychology of intergroup relations, ed. W.G. Austin and S. Worchel. Monterey, CA: Brooks/Cole.

710 Tajfel, H., and J. C. Turner. 1986. The social identity theory of intergroup behavior. In Psychology of intergroup relations, ed. S. Worchel and W. G. Austin. Chicago: Nelson-Hall. 
July 28, $2005 \quad$ 4:39 CMP $\quad$ TFJD153-03-120054

Turner, J. C. 1982. Towards a cognitive redefinition of the social group. In Social identity and intergroup relations, ed. $\mathrm{H}$. Tajfel. Cambridge: Cambridge University Press.

Turner, J. C., M. A. Hogg, P. J. Oakes, S. D. Reicher, and M. S. Wetherell. 1987. Rediscovering the social group: A self-categorization theory. Oxford: Blackwell.

Turner, R. H., and L. M. Killian. 1987. Collective behavior. Englewood Cliffs: Prentice Hall.

Unger, R. K. 2002. Them and us: Hidden ideologies-differences in degree or kind? Analyses of Social Issues and Public Policy 2(1): 43-52.

Weitzman, E. A., andand D. Kew. 2002. Responding to September 11: A conflict resolution scholar/ practitioner's perspective. Analyses of Social Issues and Public Policy 2(1): 109-118.

Willer, R. 2004. The effects of government-issued terror warnings on presidential approval ratings. Current Research in Social Psychology 10(1): 1-12. 